\title{
Commentary: Total arch replacement: Is it time to branch out?
}

\author{
Alan M. Speir, MD
}

From the Inova Heart and Vascular Institute, Falls Church, Va.

Disclosures: Author serves as a consultant on the Medtronic Cardiac Surgery Advisory Board.

Received for publication Oct 4, 2018; accepted for publication Oct 5, 2018.

Address for reprints: Alan M. Speir, MD, Inova Heart and Vascular Institute, 3300 Gallows Rd, Falls Church, VA

22042 (E-mail: alan.speir@inova.org).

J Thorac Cardiovasc Surg 2019;157:1381-2

$0022-5223 / \$ 36.00$

Copyright (c) 2018 by The American Association for Thoracic Surgery

https://doi.org/10.1016/j.jtcvs.2018.10.020

In their article in this issue of the Journal entitled, "Total Arch Replacement Using Four-Branched Graft with Antegrade Cerebral Perfusion," Minatoya and colleagues ${ }^{1}$ summarize the results of more than 1000 patients who underwent total arch replacement with a 4-branch graft between in their single center 2001 and 2015. Special emphasis was given to the operative techniques, the adjunctive cannulation options, the body temperature achieved during the interval of hypothermic circulatory arrest, and the clinical results. In their discussion section, Minatoya and colleagues ${ }^{1}$ sought to justify both why the 4-branch graft technique was superior to the technique of "island" implantation of the brachiocephalic vessels, as well as the temperature level that is used during the procedure. Although this is not the first series to have been published on this subject, Minatoya and colleagues ${ }^{1}$ are to be congratulated on the excellent results that they have achieved. Clearly, they have simplified the surgical techniques in this challenging group of patients, and their approach could be adopted by other centers with less experience to treat these challenging patients.

The in-hospital mortality was $5.2 \%$, the permanent neurologic dysfunction rate was $3.6 \%$, and the temporary neurologic dysfunction rate was $6.4 \%$. There were no spinal cord complications. The 5-year survival was $80.7 \%$, and the 10 -year survival was $63.1 \%$. These results reflect a different population in Japan of patients treated with this aortic disorder, and the volumes and expertise with this pathology eclipse those of most cardiac centers in the United States.

The central issue of this article is whether the results justify the migration from deep hypothermic circulatory arrest at $18^{\circ} \mathrm{C}$ to $22^{\circ} \mathrm{C}$ with an "island" or patch insertion of the brachiocephalic vessels to moderate hypothermia at $28^{\circ} \mathrm{C}$ with individual anastomoses to a commercially available 4-branch graft. Minatoya and colleagues ${ }^{1}$ listed several reasons that the branch graft was advantageous to the insertion of the brachiocephalic vessels as an "island" or patch. There is no question that the visualization of the individual

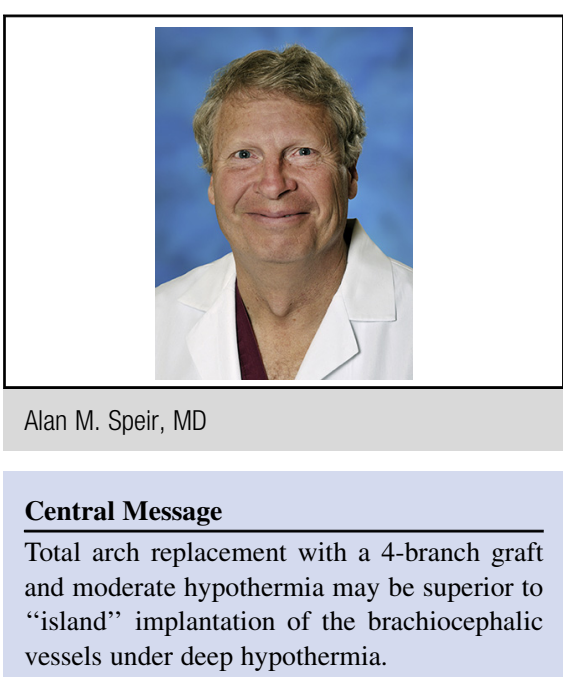

See Article page 1370.

anastomoses is easier with the branch graft than with the patch technique for facilitating hemostasis if necessary particularly along the posterior suture line of the patch. The mortality and the stroke rate were quite acceptable at moderate hypothermia of $28^{\circ} \mathrm{C}$ with antegrade cerebral perfusion, although Minatoya and colleagues ${ }^{1}$ were realistically reluctant to support that this temperature level was beneficial for all patients undergoing this complex procedure. Intraoperative neurologic monitoring was either by direct puncture of the superficial temporal artery to allow direct monitoring of pressure during the operation or by measurement of the cerebral perfusion pressure at the balloon tip of the antegrade cerebral perfusion cannula. Such rudimentary monitoring techniques still remain a major obstacle for surgeons performing these complex aortic resections in their efforts to ensure that homogeneous neuroprotection is optimized.

The genetic loading of the Japanese patients with this aortic pathology and the centralization of such patients in aortic centers specializing in the treatment of these aneurysms has yielded relevant contributions to our surgical techniques. Although many surgeons have mastered innominate or axillary cannulation with antegrade cerebral perfusion with open proximal aortic or hemiarch repairs, many are understandably reluctant to expand their treatment aggressively to the entire aortic arch because of the low volume of patients that they may encounter annually. The availability of a commercial 4-branch product, the descriptions of the surgical techniques for resection of the arch with 
antegrade cerebral perfusion, the improved visibility and resultant hemostasis with such approaches, and the improvement in coagulation profiles afforded to the surgeon with moderate rather than deep hypothermia may motivate surgeons to be more aggressive in their treatment not only of arteriosclerotic aneurysms but also of aortic dissections. As a result, surgeons confronted with such aortic pathology may wish to branch out in their surgical approach and therapy.

\section{Reference}

1. Minatoya K, Inoue Y, Sasaki H, Tanaka H, Seike Y, Oda T, et al. Total arch replacement using four-branched graft with antegrade cerebral perfusion. J Thorac Cardiovasc Surg. 2019;157:1370-8. 